\title{
Reflexiones sobre la taxonomía revisada de Bloom
}

\author{
Aly Amer \\ Facultad de Educación, Universidad Sultan Qaboos, Muscat
}

Sultanato de Oman

alyamer99@,Yahoo.com 
Reflexiones sobre la taxonomía revisada de Bloom 


\section{Resumen}

En la aplicación de la taxonomía original de Bloom, desde su publicación en 1956, se han descubierto varios defectos y limitaciones prácticas. Además, la investigación psicológica y educativa ha presenciado la introducción de varias teorías y enfoques de aprendizaje, los cuales dan a los estudiantes mayor y más responsable conocimiento sobre sus propio aprendizaje, cognición y pensamiento. Por lo tanto, un grupo de investigadores revisaron la taxonomía original para superar sus defectos, y para incorporar nuevos avances. El propósito de este trabajo es presentar una revisión crítica y concisa tanto sobre la taxonomía original, como sobre la revisada, refiriéndose a sus aspectos subyacentes de filosofía, razón, estructura y uso pedagógico potencial.

Palabras clave: Taxonomía de Bloom, original, revisada, instrucción, currículo, usos potenciales 